\title{
SUPPORTING EARLY STAGE SET-BASED CONCURRENT ENGINEERING WITH VALUE DRIVEN DESIGN
}

\author{
Bertoni, Alessandro; Bertoni, Marco \\ Blekinge Institute of Technology
}

\begin{abstract}
Set-Based Concurrent Engineering is commonly adopted to drive the development of complex products and systems. However, its application requires design information about a future product that is often not mature enough in the early design stages, and that it is not encompassing a service and lifecycleoriented perspective. There is a need for manufacturers to understand, since the early design stages, how customer value is created along the lifecycle of a product from a hardware and service perspective, and how to use such information to screen radically new technologies, trade-off promising design configurations and commit to a design concept. The paper presents an approach for the multidisciplinary value assessment of design concepts in sub-systems design, encompassing the high-level concept screening and the trade-off of different design concepts, and enabling the integration of value models results into a Set-based Concurrent Engineering process. The approach is described through its application in the case study of the development of a subsystem component for a commercial aircraft engine.
\end{abstract}

Keywords: Value Driven Design, Systems Engineering (SE), Decision making, Early design phases, Case study

Contact:

Bertoni, Alessandro

Blekinge Institute of Technology

Mechanical Engineering

Sweden

alessandro.bertoni@bth.se

Cite this article: Bertoni, A., Bertoni, M. (2019) 'Supporting Early Stage Set-Based Concurrent Engineering with Value Driven Design', in Proceedings of the 22nd International Conference on Engineering Design (ICED19), Delft, The Netherlands, 5-8 August 2019. DOI:10.1017/dsi.2019.243 


\section{INTRODUCTION}

Industrial companies struggle when integrating a new design or a new technology into complex industrial product development projects (Isaksson et al., 2016). This is often true when the product under development is a safety- and performance-critical component, such as in the case of aerospace product development. The complexity of the development renders a situation in which engineers, when making early-stage design decisions, struggle to understand the impact that a new design might have on the performances of the overall system. In such context, to support multidisciplinary analysis, development activities are commonly performed in the frame of Set-Based Concurrent Engineering (SBCE) (Sobek et al., 1999). The key logic of SBCE is to find a solution as an intersection of a number of feasible parts, developed with relative independence, and use later additional information to reduce the sets of possible solutions (Sobek et al., 1999). Literature shows several examples of decision support tools for SBCE. Those typically require a great deal of data and information to gradually narrow down a set of potential design solutions, eliminating those falling in the regions of the design space that are proven unfeasible (Malak et al., 2009). SBCE has proved to be effective in reducing the risk of design iterations (Johannesson, et al., 2015), but appears to be more suitable for post-embodiment design (Inoue et al., 2010; Qureshi et al., 2010; Canbaz et al., 2014). In preembodiment design, instead, abstract models and experience from previous projects are still found to drive the elimination of design sets (Levandowski et al., 2014).

Researchers in Value Driven Design (VDD) (Collopy and Hollingsworth, 2011; Monceaux et al., 2016) have focused on such early design stages, proposing the use of "value models" to estimate the monetary benefit of a design alternative while focusing on the overall system value (e.g. Cheung et al., 2012; Isaksson et al., 2013). VDD shares with the literature on Value Engineering (Park, 2017) and TradeSpace exploration (Ross et al., 2004) the use of "value" as a proxy to measure the 'goodness' (see Cheung et al., 2012) of design decisions for complex systems. In VDD the focus lies on pre-embodiment design and on the opportunity to support the analysis of the design space from a multidisciplinary perspective.

The aim of the paper is to present an approach based on VDD methods to enable the multidisciplinary assessment of early design concepts in sub-systems design. The approach focuses on pre-embodiment design and it is executed as initial activity of a SBCE effort. It encompasses both the screening of possible technologies and the assessment of different design concepts in the feasible design space from a value perspective. The approach is based on the Technique for Order of Preference by Similarity to Ideal Solution (TOPSIS) (Kim et al., 1997), a multi-criteria decision analysis method for technology screening, and it further adopts an extended version of the EVOKE approach (Bertoni et al., 2018) to enable the automatic calculations of the design merit of multiple design variations in the feasible design space. The approach is described in the paper through its application to the case study of the development of a new generation turbine rear structure (TRS) for a commercial aircraft engine.

The paper is organized in the following structure. Section 2 describes the research approach based on participatory action research in the frame of the Design Research Methodology. Section 3 provides an overview of the main value assessment methods in early design. Section 4 presents the rationale of the proposed approach and the description of the case study. Section 5 discusses the relevancy of the finding in light of the current literature on VDD and SBCE and draws the final conclusions.

\section{RESEARCH APPROACH}

Participatory action research (PAR) (Whyte, 1991) is the approach at the basis of the work presented in this paper. The adoption of a PAR involved the direct participation of both researchers and practitioners in the research design and development (Whyte, 1991). Both data collection and the problem definition were run in collaboration with a sub-system manufacturer operating in the aerospace industry. Data were collected through structured and unstructured interviews facilitated by the frequent presence of the researchers at the case company.

The data collected encompassed needs identification (including the definition of company values and strategy), the description of the current state of practice, the definition of functional requirements and performance requirements for aircraft engine and engine components, and the identification of key design parameters for the turbine rear structure. Those data were used to create preliminary value models that were iteratively improved and detailed by means of feedback loops with industry experts. 
The validity, the rationale and the logic of the approach were verified and refined through a number of workshops and interviews run with the industrial partner. A cross-disciplinary group of experts was involved in the validation activity encompassing expertise in product development, knowledge-based systems, platform development, and engine systems integration.

The overall research effort can be framed in the Design Research Methodology (DRM, Blessing and Chakrabarti, 2009), with the proposed approach for multidisciplinary value assessment corresponding to the results of the "Prescriptive Study" stage, building on the research challenges identified through focus groups, semi-structured interviews, and iterative feedback loops. Literature on established approaches for value assessment in VDD has contributed to the selection of the methods combined in the final proposal. The validation of the impact of the approach corresponds to the "Support Evaluation" phase of the DRM, aimed at ensuring that the 'actual support' was developed to such an extent that it could be evaluated. Due to the length and the complexity of new aerospace development projects, the work presented in this paper does not encompass the stages of the "Descriptive Study II" concerning the "Application Evaluation" and the "Success Evaluation" phases. Figure 1 summarizes the research approach adopted and visualizes the relation between the participatory action research approach and the DRM.

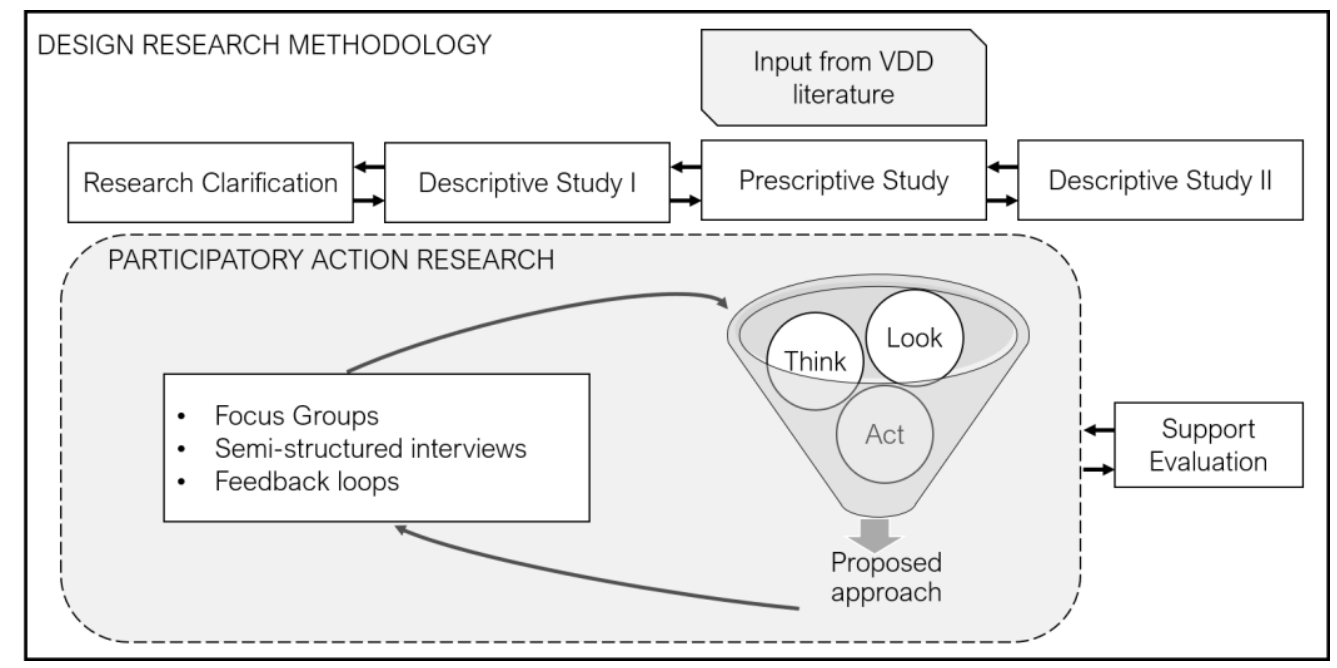

Figure 1. The research approach highlighting the link between participatory action research and the design research methodology

\section{ASSESSING VALUE IN EARLY DESIGN}

The successful identification of the value proposition, the understanding of the most vulnerable part of the business, and the assessment of the core sources of internal and external value generation, are the three key abilities for a company to run a sustainable business (Fine et al., 2002).

There is today an increased interest in literature towards design decision support that increases awareness of how much customers 'value' certain capabilities against each other, so to orient trade-off resolution towards value maximization (Castagne et al., 2009; Collopy and Hollingsworth, 2011; Cheung et al., 2012; Isaksson et al., 2013). However, value identification is multi-dimensional in nature and the concept of value itself is often perceived, and defined, differently by different stakeholders. Value can be perceived merely as the ratio between performance and cost (Miles, 1962), or dependent from the amount of money a customer is willing to pay (Shapiro and Jackson, 1978), or again as dependent by the individual experience of each user while the product is "in-use" (Normann and Ramirez, 1993). The first two definitions see value as a quantitative monetary measure, the last implies a subjective interpretation of it by the customer. However, in an early design phase, reliable monetary models are rarely available due to the lack of data and information. At the same time, measuring the subjective "in-use" customer experience is very challenging for first- and second- tier suppliers, making also little sense due to their business-to-business focus.

Authors in the field of systems engineering have proposed value-based methodologies to improve the awareness of the system value along the entire requirements decomposition process. Value Driven Design (Collopy and Hollingsworth, 2011), is an example of such systems engineering strategies promoting the use of multidisciplinary analysis and optimization in design, ultimately leading to the idea of using value models in early design stages to enhance engineers' awareness about the problem to be solved from a 
multidisciplinary perspective. Those value models have been proved to be useful both as boundary objects (Carlile 2002), around which the value discussion develops (Panarotto, 2015), and as tools for the preliminary assessment of the "goodness" of a design (Cheung et al., 2012). Value has also been related to the capability of maintaining or improving the system functions in the presence of changes (McManus et al., 2007), and to the evaluation of system robustness under changing process conditions (Ross et al., 2008). Furthermore, Steiner and Harmon (2009) have stressed the importance of modeling "intangibles" associated with knowledge, emotions, and experience. Emerging from research in aerospace product development Bertoni et al. (2013) have defined value from the perspective of a sub-system manufacturer as the overall "level of fulfillment" of internal and external stakeholders' needs along the lifecycle of a product, encompassing customers, manufacturers, institutions and the environment. This definition of value is the one adopted in the approach presented in the paper.

\section{MULTIDISCIPLINARY VALUE ASSESSMENT OF SUB-SYSTEMS CONCEPTS: RATIONALE AND CASE STUDY}

\subsection{Case study: development of an aero-engine turbine rear structure (TRS)}

The TRS is a major static component in commercial and military jet engines. Its main functions are to lead the core gas flow from the low-pressure turbine (LPT) to the nozzle of the engine, and to convey mechanical loads between the airplane wing and the engine via mounting lugs (see: Lewandowsky et al., 2014). Additionally, it is designed to contain disintegrating parts from the neighboring LPT in case of failure, preventing them from leaving the engine and potentially penetrating the fuselage. Importantly, being a critical component for the entire aero-engine system, the TRSs for different engine models differ extensively in their design, and essentially every surface of the final component is customized to the requirements at hand. The development of the TRS is a requirements-driven process that follows a setbased concurrent engineering approach, featuring several iterations (Lewandowsky et al., 2014). The design activities kick-off by defining constraints at the system level, including temperature ranges, stiffness, weight, and design of neighboring sub-systems. Then the set of design solutions is narrowed down gradually as the product specifications become more detailed, leading to one final solution, rather than freezing the bandwidth of functionality and performance already in a very early stage as it happens with more conventional platform-based development. Importantly, the knowledge created in the setbased exercise is reused in future products, and to gain scalability in design.

\subsection{High-level process view of the multi-disciplinary value assessment approach}

In the proposed approach, the traditional requirement-driven approach for the development of an aerospace component is complemented by an early design space exploration. The kick off a new development project is given by either the formulation of new needs and expectations for a future product by a customer or by the internal company decision to estimate the potential of a new technologyies. In both cases, the proposed approach starts with the definition of a Value Creation Strategy (VCS), which is used as the basis for defining promising design concepts ideas, without specifying detailed design solutions for them. This document carries preliminary design information about the context of a specific project, translating the needs of the stakeholders, directly and indirectly, involved in the project (Isaksson et al., 2013).

The first activity of the case study was, therefore, to identify and formalize stakeholders needs and expectations to create a first VCS. An initial workshop including representatives from the case company and representative from suppliers was organized to set the context of the development effort and collect initial needs and expectations. A follow-up workshop was then organized with the presence of companies' specialists in product development to formalize a more detailed list of expectations encompassing, more in detail, company internal needs (e.g. production and development efficiency). As a result, a document listing 15 needs in the case of a high-performance solution and 17 needs in case of a low-cost solution, was defined and the related stakeholders were identified. To each need, a list of Value Drivers who had a direct impact on the satisfaction of the need was identified. The next step was taken by the researchers who categorized the needs, clustered them, and analyzed redundancy and hierarchical structure. This rendered 6 clusters of needs defined as 'value dimensions', and 20 'value drivers'. The latter represent directions that seem to have a significant influence on the value perceived by the customer (or by the stakeholders) in a given problem context. Table 1 shows the complete list of value dimensions and drivers identified in the case study. 
Table 1. Identified dimensions and drivers in the value creations strategy

\begin{tabular}{|c|c|c|}
\hline Value Dimensions & & Drivers \\
\hline $\begin{array}{ll}\text { - } & \text { Aircraft operations } \\
\text { - } & \text { Emissions } \\
\text { - } & \text { Servicing } \\
\text { - } & \text { Development efficiency } \\
\text { - } & \text { Risk } \\
\text { Production Efficiency }\end{array}$ & $\begin{array}{ll}\text { - } & \text { Specific thrust } \\
\text { - } & \text { Specific fuel } \\
\text { consumption } \\
\text { - } & \text { Noise } \\
\text { - } & \text { Cost saving per flight } \\
\text { - } & \text { NOx emissions } \\
\text { - } & \text { CO2 emissions } \\
\text { - } & \text { Material Criticality } \\
\text { - } & \text { Reliability } \\
\text { - } & \text { Maintainability } \\
\text { - } & \text { Robustness }\end{array}$ & $\begin{array}{ll}\text { - } & \text { Knowledge acquisition } \\
\text { - } & \text { Development cost } \\
\text { - } & \text { Development lead-time } \\
\text { - } & \text { Supplier availability } \\
\text { - } & \text { Technology risk } \\
\text { - } & \text { Market risk } \\
\text { - } & \text { Scalability of } \\
\text { manufacturing } \\
\text { - } & \text { Manufacturing cost } \\
\text { - } & \text { Production lead time } \\
\text { - } & \text { Commonality }\end{array}$ \\
\hline
\end{tabular}

\subsection{Concept screening with the TOPSIS approach}

At this stage, explicitly or implicitly, all design teams traditionally use some methods to generate ideas and choose among solution options. Those range from multi-voting, to the identification of a product champion, from the elicitation of pros and cons to external decisions. Still, a structured and systematic method offers several benefits, as it helps to maintain objectivity throughout the concept phase of the development process and guides the product development through a critical, difficult and sometimes emotional process. A plethora of decision matrixes has been developed in literature to encourage decision making based on objective criteria and to minimize the likelihood that arbitrary or personal factors influence the definition of a concept. In the proposed approach, during the selection of which method to be used to support complex systems early-stage design decisions, attention was put on the fact that such decisions are characterized by the involvement of multiple stakeholders from different disciplines and specific expertise. Furthermore, easiness of use and ability to deal with a limited amount of inputs to perform the calculation were also factors playing an important role in the selection of the decision method. To deal with such needs, the proposed approach features the use of TOPSIS (an acronym for Technique for Order of Preference by Similarity to Ideal Solution) (Kim et al., 1997), a decision matrix to support early-stage concept selection activities. The TOPSIS method is based on five computation steps. The first step is the gathering of the performances of design alternatives across the different selection criteria, which are then normalized in a second step. The normalized scores are then weighted: a weighted normalized decision matrix is constructed by multiplying the normalized scores by their corresponding weight. The weighted scores are then used to compare each action to an ideal (zenith) and anti-ideal (or nadir or negative ideal) virtual action. Eventually, the distance between each ranked design, zenith, and nadir is calculated using Euclidean distance or Manhattan metric. Finally, the score assigned to a design is calculated as the ratio of these distances. According to Kim et al. (1997) and Shih et al. (2007) the use of TOPSIS brings a number of benefits compared to more traditional techniques, mainly because it features a logic mirroring the rationale of human choice, and because it emphasizes the value of extreme solutions (i.e., radical designs) over weighted compromises.

In the case study, the VCS served as input for the high-level concept screening run with the TOPSIS method. Here the relative value of six high-level concept definitions (such as, innovative materials, heat shield technology, electrical generator, etc.) was estimated simulating a situation in which five independent decision makers express their preferences for a new technology or design. As a result, the use of innovative material was selected as a relevant concept to bring forward to the concept trade-off.

\subsection{Trade-offs with an extended EVOKE approach}

The last step of the process focuses on running the trade-off analysis on a number of design variations of the concepts identified with TOPSIS. This step is based on the application of an extended version of the EVOKE (Early Value Oriented Design Exploration with Knowledge Maturity) approach (Bertoni et al., 2018). EVOKE initially cascades down VCS information into a list of rank-weighted value drivers that is relevant for the specific technology development project at hand. A so-called Weighting matrix supports the engineering design and management team in mapping these two perspectives, producing a list of rank 
weighted value drivers for the technology. This information is later used to calculate the design merit scores for each proposed solution. Two features have been added to the EVOKE approach. The first consisted in the automatization the EVOKE computation, so to expand the assessment to potentially hundreds of different design variations, rather than to a restrict number of design alternatives. The second consisted in the definition of feasibility boundaries for the engineering characteristics, to automatically exclude design configurations not fulfilling the minimum requirements. In the case study, each of the 20 value drivers featured in Table 1 was rank-weighted based on their importance for the TRS project and based on their correlation with the value dimensions, tuning them on the basis of the specific preferences of the customer tier under consideration.

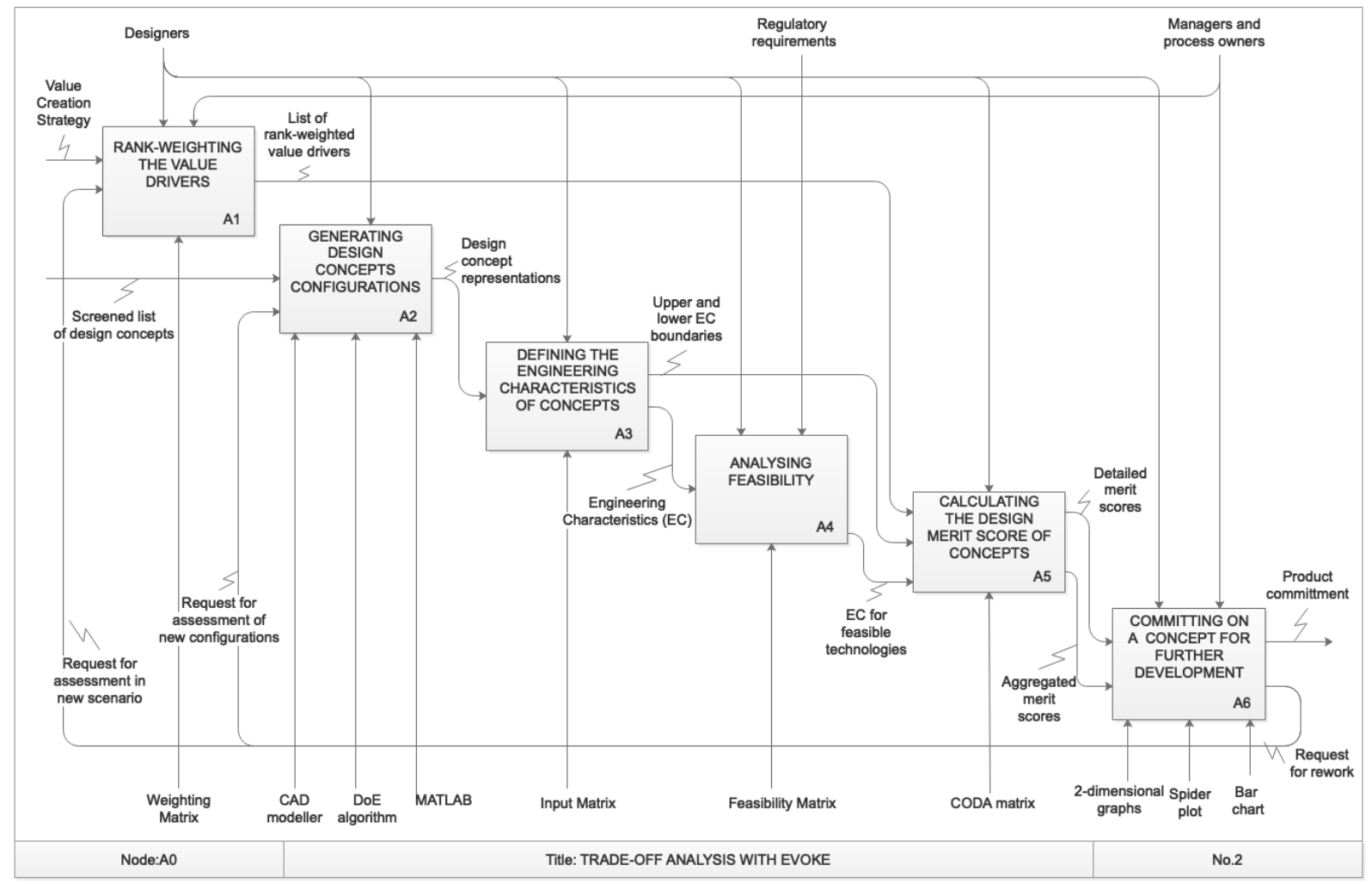

Figure 2. IDEFO representation of the EVOKE approach with the extended features of automatization and feasibility analysis (adapted from Bertoni et al., 2016)

The second step foresees the creation of several (and more detailed) configurations of the design concepts screened by the TOPSIS matrix. The increased maturity of the concept description suggests creating parametric 3D geometrical and functional representations of each 'screened' solutions, using a Design-of-Experiment (DoE) approach. The DoE can automatically generate a high number of design configurations, to obtain information, by means of simulation, on their geometrical and structural performances. The main reason for this task is that the design space can theoretically include an almost unlimited number of possible design configurations with peculiar mechanical and lifecycle performances. Those are described in the form of a list of Engineering Characteristic (EC), which are collected in the so-called Input matrix. EC represents design parameters that distinguish each configuration from a give baseline design (e.g., an existing solution or a competitor's product). These may include geometrical and physical dimensions, aspects related to manufacturability, maintainability, and recycling. They may also feature more intangible aspects, such as the availability of resources within the enterprise (to support product design and realization), as well knowledge reuse. The DoE approach can potentially create hundreds or thousands of different design variations of preselected concepts in a short timeframe, based on the selected algorithm.

All design variations produced goes through a Feasibility analysis, which featured critical operational thresholds for the solution. In the case of the TRS, operating temperature, fatigue life, and compliance to REACH legislation (European Commission, 2006) were considered main constraints for the design. These thresholds were case study specific: they reflected the physical properties of the materials to 
verify the feasibility of the concepts. For instance, temperatures higher than the melting point would automatically flag the concept as unfeasible without further need for investigation.

The CODA (Customer Oriented Design Analysis) matrix (Eres et al., 2014) is then used to compute a value score, also called "design merit", for each feasible option. CODA features both correlations a non-linear merit functions expressing the desired direction of improvement (Maximization, Minimization, Optimization, Avoidance) between each ECs and value drivers. In the TRS example, the CODA matrix was populated correlating the 18 ECs with the 20 value drivers. This resulted in a CODA matrix with potentially 360 correlations and relative non-linear functions to be set. In reality, only a limited subset of correlations was found to be relevant, sensibly reducing the time required to fill in the matrix. At the end of this step, the design merit of each concept is outputted as a percentage of the satisfaction of the overall set of stakeholders' needs. The automatization of the EVOKE approach was obtained by importing the results from the DoE simulations into the Input matrix and iteratively test the data of each design variation in the CODA matrix, exporting and saving the design merit score for each design case. Figure 3 shows part of the results of the automatized EVOKE process visualized in a two-dimensional matrix. Each point and corresponding design number in Figure 3 visualize the design merit score obtained in EVOKE for each design variation studied in the DoE. Based on such results the most interesting design variation to further investigate could be selected for further analysis. A visualization interface (Figure 4) was developed to enable the engineering teams to play with the results and explore the value analysis to a deeper level of detail, analyzing the value contribution for each value driver (as shown in the right-hand side of Figure 4). Furthermore, the visualization interface allowed to test changes in the VCS and operational threshold, to evaluate the robustness and sensitivity of the value results under different conditions (as shown in the left-hand side of Figure 4).

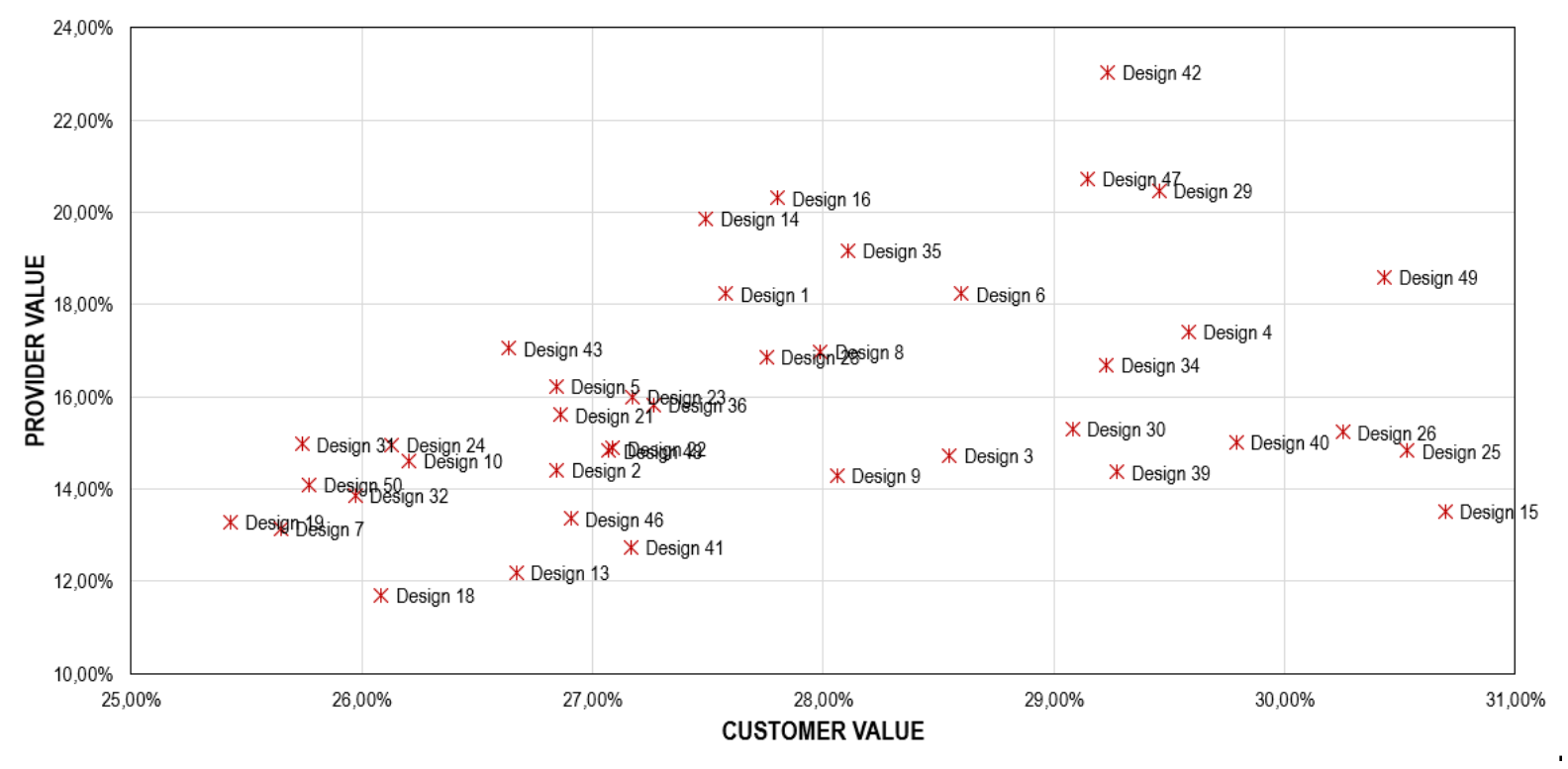

Figure 3. Two-dimensional graph displaying EVOKE results.

For the sake of simplicity, the following description considers only 3 alternative TRS design variations, featuring similar geometrical properties but differing in terms of material. Hence, material density, tensile strength, heat capacity, and thermal expansion coefficient are among the most important criteria being inserted in the EVOKE input matrix. Figure 4 displays the design merits obtained from EVOKE for three different materials (Inconel, 3M Nextel 610 and Nippon Carbon HiNicalon), as well as the results of the feasibility check. The main aim of this interface is to enable value-oriented consideration to become a complementary part of the "sets" of variable and parameters that are studied to delimit the feasible and desirable design space prior to embodiment design. 

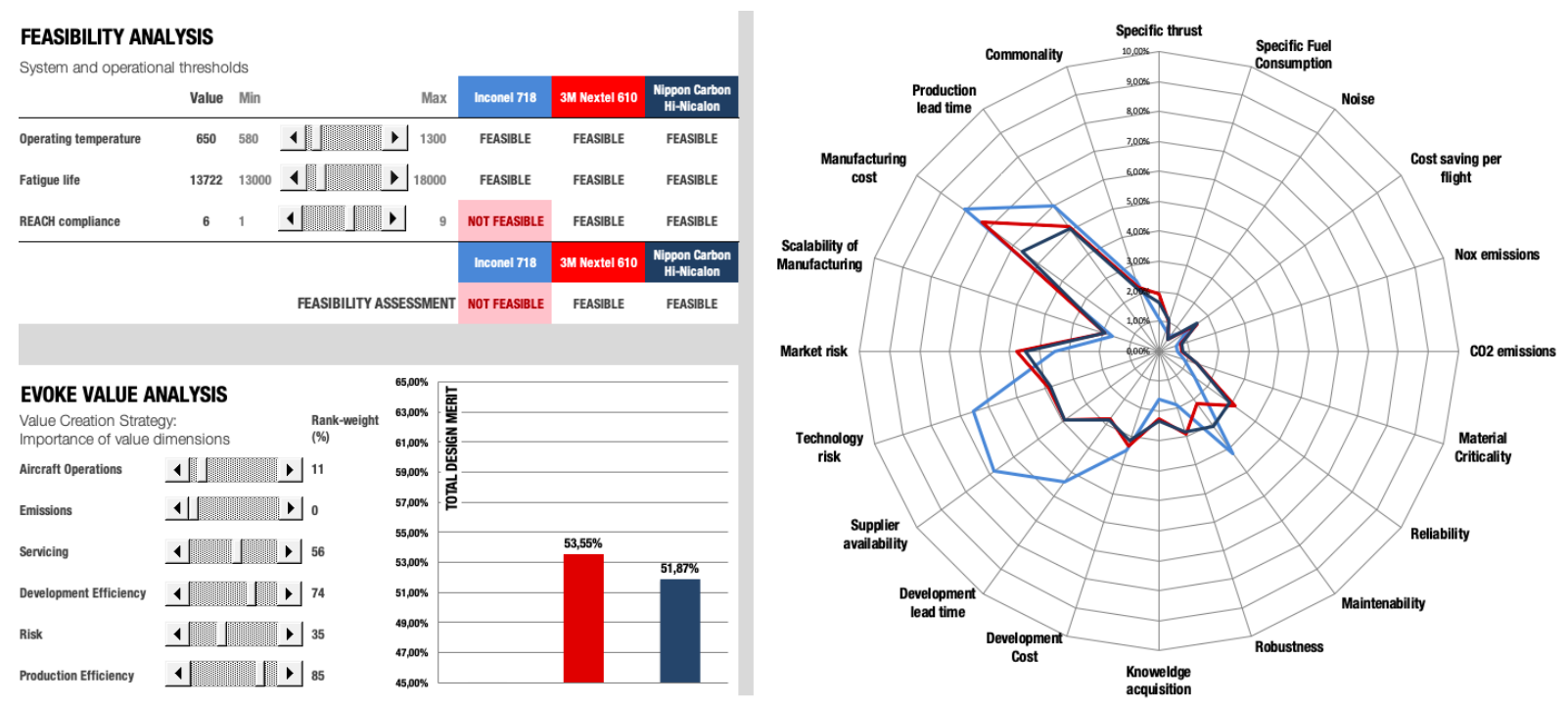

Figure 4. EVOKE analysis results for the three selected design alternatives based on different materials.

\section{CONCLUDING REMARKS}

The paper has presented an approach for the multidisciplinary value assessment of sub-system concepts that has been developed and exemplified in the context of aerospace product development from the perspective of a sub-system manufacturer. The proposed approach is meant to be used during early stages of product development where technologies are screened, and the design space is explored. The approach is grounded on previous research proposing the definition of a Value Creation Strategy as the high-level driving entity of early design decisions. The paper contributes to the methods currently discussed in the value-driven design literature, by proposing two additional features to characterize the value assessment and decision-making process. First, it proposes the use of the TOPSIS approach as a technique to allow technology screening, after the definition of a VCS. Second, it proposes an extended application of the EVOKE approach enabled by the capability us using the results of the DoE analysis to populate the EVOKE Input matrix. The extension allows the automatic computation of the design merit of potentially hundreds of design variants in a restrict timeframe (less than one second per variant in the presented case study). Thanks to this ability, the use of the EVOKE approach can be seen as no longer only limited to the reactive analysis of a limited amount of predefined design concepts, rather it could be used as a proactive method to dynamically explore the design space, in search for combinations of engineering characteristics that render highly valuable design solutions. Additionally, to improve the efficiency of the calculation, avoiding computing unfeasible solutions, the definition of feasibility boundaries was added in EVOKE. Finally, the approach also features the interactive visualization of the compiled results in a decision-making environment. Such feature was already present in the original formulation of EVOKE, however the automatic computation of the design merit for hundreds (or even thousands) design variations asked for a visualization interface capable to deal with a high number of solution points (as shown in Figure 3 ), eventually enabling the interactive selection of the solutions perceived as most interesting to investigate by the engineers.

The aerospace context, thanks to its relatively static products architectures, and the stringent objectives on greenhouse gas reduction, has proven to be a suitable context for the development of the approach. Nonetheless, the EVOKE method had been previously developed and validated in the frame of aerospace product development research (Bertoni et al., 2018).

The research presented in this paper has contributed to introducing a new perspective in the area of Value-Driven Design by establishing a working method allowing value modeling activities to evolve from pure qualitative assessment for high-level concept screening, to synergize with numerical simulations in the pre-embodiment design. Such integration has been implemented with reduced functionalities in a demonstrator in the Model-Driven Decision Arena (Bertoni et al., 2018b). Such implementation has the potential for further development and standardization of the design practice and, nonetheless, brings the approach to a higher readiness level so to be able to test it in real case scenarios. 
In terms of generalizability, the approach has been developed and tested in a specific industrial context and it is therefore not possible to claim the generalization to other fields prior to further verification. It is, however, to be remarked that the single methods applied in the model (TOPSIS and EVOKE) have been previously tested and validated as stand-alone solutions in a number of industrial situations even outside the aerospace industry, and that no particular reasons against their use in other contexts have been identified. In terms of verification of industrial benefits, the long development process of aerospace products renders a situation in which it is difficult to practically verify the impact of the approach in terms of lead time reduction, customer satisfaction or revenue generation, whose complete effects will need to be verified in future research. Future work will also need to focus more on the integration of relevant criteria to embed sustainability considerations. Those are marginally touched in the proposed approach by integrating a sustainability perspective in the value drivers definition, but they do not appear to be exhaustive in relation to the current literature on sustainability indicators for new product development. An additional improvement currently under research concerns the use of data mining techniques to compensate the lack of quantitative data inputted in the EVOKE approach, although the status of the research is still immature to be integrated into the present publication.

\section{REFERENCES}

Bertoni, A., Bertoni, M. and Isaksson, O. (2013), "Value visualization in Product Service Systems preliminary design", Journal of cleaner production, Vol. 53, pp. 103-117. https://doi.org/10.1016/j.jclepro.2013.04.012

Bertoni, A., Levandowski, C., Isaksson, O. and Larsson, T. (2016), "Virtual Modeling for Lifecycle Performance Assessment in aerospace design”, Procedia CIRP, Vol. 47, pp. 335-340. https://doi.org/10.1016/j.procir.2016.03.219

Bertoni, M., Bertoni, A. and Isaksson, O. (2018), "Evoke: A value-driven concept selection method for early system design”, Journal of Systems Science and Systems Engineering, Vol. 27 No. 1, pp. 46-77. https://doi.org/10.1007/s11518-016-5324-2

Bertoni, M., Wall, J. and Bertoni, A. (2018b), "Model Driven Decision Arena: an aerospace study", In International Design Conference, Dubrovnik (pp. 171-182). The Design Society. https://doi.org/10.21278/idc.2018.0326

Blessing, L.T. and Chakrabarti, A. (2009), DRM, a design research methodology, Springer Science and Business Media. https://doi.org/10.1007/978-1-84882-587-1_2

Canbaz, B., Yannou, B. and Yvars, P.A. (2014), "Improving process performance of distributed set-based design systems by controlling wellbeing indicators of design actors", Journal of Mechanical Design, Vol. 136 No. 2, p. 021005. https://doi.org/10.1115/1.4026034

Carlile, P.R. (2002), “A Pragmatic View of Knowledge and Boundaries: Boundary Objects in New Product Development”, Organization Science 2002, Vol. 13 No. 4, pp. 442-55. https://doi.org/10.1287/orsc.13.4.442.2953

Castagne, S., Curran, R. and Collopy, P. (2009), "Implementation of value-driven optimisation for the design of aircraft fuselage panels", International journal of production economics, Vol. 117 No. 2, pp. 381-388. https://doi.org/10.1016/j.ijpe.2008.12.005

Cheung, J., Scanlan, J., Wong, J., Forrester, J., Eres, H., Collopy, P., Hollingsworth, P., Wiseall, S. and Briceno, S. (2012), "Application of value-driven design to commercial aeroengine systems", Journal of Aircraft, Vol. 49 No. 3, pp. 688-702. https://doi.org/10.2514/1.C031319

Collopy, P.D. and Hollingsworth, P.M. (2011), "Value-driven design", Journal of aircraft, Vol. 48 No. 3, pp. 749-759. https://doi.org/10.2514/1.C000311

Eres, H., Bertoni, M. and Scanlan, J. (2014), "Mapping customer needs to engineering characteristics: an aerospace perspective for conceptual design”, Journal of Engineering Design, Vol. 25 No. 1-3, pp. 64-87. https://doi.org/10.1080/09544828.2014.903387

European Commission (2006), EC No 1907/2006. [online] available at https://ec.europa.eu/growth/sectors/chemicals/legislation_en accessed on March 19th, 2019.

Fine, C.H., Vardan, R., Pethick, R. and El-Hout, J. (2002), "Rapid-Response Capability In Value-Chain Design", MIT Sloan Management Review. https://doi.org/10.1.1.127.1479

Inoue, M., Nahm, Y.E., Okawa, S. and Ishikawa, H. (2010), "Design support system by combination of 3D-CAD and CAE with preference set-based design method", Concurrent Engineering, Vol. 18 No.1, pp. 41-53. https://doi.org/10.1177/1063293X09360833

Isaksson, O., Bertoni, A., Levandowski, C., Müller, J., Wiklund, D. and Johansson, P.B.V. (2016), "Virtual contextual validation of technologies and methods for product development", In DS 84: Proceedings of the DESIGN 2016 14th International Design Conference (pp. 669-678). 
Isaksson, O., Kossmann, M., Bertoni, M., Eres, H., Monceaux, A., Bertoni, A., Wiseall, S. and Zhang, X. (2013, June), "Value-Driven Design-A methodology to Link Expectations to Technical Requirements in the Extended Enterprise", In INCOSE International Symposium (Vol. 23, No. 1, pp. 803-819). https://doi.org/10.1002/j.2334-5837.2013.tb03055.x

Johannesson, H., Landahl, J., Levandowski, C. and Raudberget, D. (2017), "Development of product platforms: Theory and methodology”, Concurrent Engineering, Vol. 25 No. 3, pp. 195-211. https://doi.org/10.1177/1063293X17709866

Kim, G., Park, C.S. and Yoon, K.P. (1997), "Identifying investment opportunities for advanced manufacturing systems with comparative-integrated performance measurement", International Journal of Production Economics, Vol. 50 No. 1, pp. 23-33. https://doi.org/10.1016/S0925-5273(97)00014-5

Levandowski, C., Michaelis, M.T. and Johannesson, H. (2014), "Set-based development using an integrated product and manufacturing system platform”, Concurrent Engineering, Vol. 22 No. 3, pp. 234-252. https://doi.org/10.1177/1063293X14537654

Malak Jr, R. J., Aughenbaugh, J.M. and Paredis, C.J. (2009), "Multi-attribute utility analysis in set-based conceptual design”, Computer-Aided Design, Vol. 41 No. 3, pp. 214-227. https://doi.org/10.1016/j.cad.2008.06.004

McManus, H.M., Richards, M.G., Ross, A.M. and Hastings, D.E. (2007), “A Framework for Incorporating "ilities" in Tradespace Studies”, AIAA Space 2007, Long Beach, CA. https://doi.org/10.2514/6.2007-6100

Miles, L.D. (1962), Techniques of Value Analysis and Engineering, McGraw-Hill, New York.

Monceaux, A., Kossmann, M., Wiseall, S., Bertoni, M., Isaksson, O., Eres, H., Bertoni, A. and Rianantsoa, N. (2014), "Overview of Value-Driven Design Research: Methods, Applications, and Relevance for Conceptual Design", Insight, Vol. 17 No. 4, pp. 37-39.

Normann, R. and Ramirez, R. (1993), "From value chain to value constellation: Designing interactive strategy", Harvard business review, Vol. 71 No. 4, pp. 65-77.

Panarotto, M. (2015), A Model-Based Methodology for Value Assessment in Conceptual Design (Doctoral dissertation, Blekinge Tekniska Högskola). ISBN: 978-91-7295-316-1

Park, R. (2017), Value engineering: a plan for invention, Routledge. ISBN: 1-57444-235-X

Qureshi, A.J., Dantan, J.-Y., Bruyere, J. and Bigot, R. (2010), "Set based robust design of mechanical systems using the quantifier constraint satisfaction algorithm", Engineering Applications of Artificial Intelligence, Vol. 23 No. 7, pp. 1173-1186. https://doi.org/10.1016/j.engappai.2010.02.003

Ross, A.M., Hastings, D.E., Warmkessel, J.M. and Diller, N.P. (2004), "Multi-attribute tradespace exploration as front end for effective space system design", Journal of Spacecraft and Rockets, Vol. 41 No. 1, pp. 20-28. https://doi.org/10.2514/1.9204

Ross, A.M., Rhodes, D.H. and Hastings, D.E. (2008), "Defining changeability: Reconciling flexibility, adaptability, scalability, modifiability, and robustness for maintaining system lifecycle value", Systems Engineering, Vol. 11 No. 3, pp. 246-262. https://doi.org/10.1002/sys.20098

Shapiro, B.P. and Jackson, B.B. (1978), "Industrial pricing to meet customer needs", Harvard Business Review, Vol. 56 No. 6, pp. 119-127.

Shih, H.S., Shyur, H.J. and Lee, E.S. (2007), “An extension of TOPSIS for group decision making”, Mathematical and Computer Modelling, Vol. 45 No. 7, pp. 801-813. https://doi.org/10.1016/j.mcm.2006.03.023

Sobek II, D.K., Ward, A.C. and Liker, J.K. (1999), “Toyota's principles of set-based concurrent engineering”, MIT Sloan Management Review, Vol. 40 No. 2, p. 67.

Steiner, F. and Harmon, R. (2009), "The Impact of Intangible Value on the Design and Marketing of New Products and Services: An Exploratory Approach”, Proceedings of PICMET 2009. Portland, Oregon USA. https://doi.org/10.1109/PICMET.2009.5261890

Whyte, W.F. (1991), "Participatory action research: Through practice to science in social research", Participatory action research, pp. 19-55. https://doi.org/10.1177/000276428903200500

\section{ACKNOWLEDGEMENTS}

The research has received financial support from the Swedish Knowledge and Competence Development Foundation through the Model Driven Development and Decision Support research profile at Blekinge Institute of Technology, and from the Swedish Governmental Agency for Innovation Systems (VINNOVA), in the frame of the NFFP \& VITUM project. 